\title{
Da literatura ao cinema: a estética naturalista francesa na cultura brasileira oitocentista*
}

Pedro Paulo Garcia Ferreira Catharina ${ }^{a}$

\begin{abstract}
Resumo
Este artigo aborda a presença da literatura naturalista francesa no Brasil desde a segunda metade do século XIX até 1914, destacando sua importância e diversidade no campo literário brasileiro e sua sobrevivência por meio da associação com outras formas de arte, como o teatro e o cinema. Para provar seu argumento, apresenta dados comprobatórios da circulação das obras de escritores naturalistas franceses durante todo o período, atingindo público variado, além de mostrar a atuação destes últimos fora da esfera literária propriamente dita, influenciando a moda e os costumes.
\end{abstract}

Palavras-chave: estética naturalista; cultura brasileira; imprensa brasileira; teatro naturalista; cinema.

* Esta pesquisa vem 
O leitor e a leitora que, em 10 de janeiro de 1884, sentados na confeitaria Paschoal da rua do Ouvidor ou no conforto de seus lares, folheavam o exemplar da Gazeta de Notícias do Rio de Janeiro, encontravam à página 2 a notícia de uma curiosa novidade da moda:

\section{O BRACELETE LITERÁRIO}

A moda, inesgotável nas suas invenções, acaba de descobrir um novo bracelete, que vai fazer furor na alta roda feminina - é o bracelete literário. Este bracelete compõe-se de doze pequenas moedas de ouro enfiadas em uma dupla cadeia. No reverso das moedas lê-se o nome, em esmalte, dos autores favoritos.

Cada pulseira equivale a uma espécie de confissão. Por exemplo, as senhoras que preferirem a literatura naturalista usarão os nomes de Zola, Goncourt, Maupassant, Eça de Queirós, Aluísio Azevedo, etc. As senhoras inclinadas à escola romântica adotarão nos seus braceletes os nomes de Rousseau, Byron, Musset, Garrett, Macedo, etc.

As amantes do classicismo usarão o nome de Racine, Corneille, Montaigne, Fr. Luiz de Souza, Vieira, Magalhães, etc.

As ecléticas confundirão os nomes de Balzac, Alexandre Dumas filho, Shakespeare, George Sand, Hugo, Voltaire, Michelet, Daudet, Camillo, Herculano, Latino, Bulhão Pato, Alencar, etc. [...]

Esta notícia, que reúne em um mesmo "bracelete literário" escritores franceses, ingleses, portugueses e brasileiros, já havia sido publicada em 20 de dezembro de 1883 no jornal A Pacotilha, do Maranhão, com o título "Atualidade Europeia" - provavelmente já sendo uma tradução de notícia de um jornal europeu. Porém, nota-se que não continha os escritores brasileiros inseridos pela folha carioca, que também mudou seu título e introduziu pequenas modificações. A apropriação do anúncio maranhense pela Gazeta de Notícias e a inclusão de nomes de escritores brasileiros dos diferentes movimentos literários apontam para uma circulação internacional de ideias e estéticas, na qual o Brasil se via naturalmente inserido, e 
para o compartilhamento de gostos que não se restringiam a fronteiras e nacionalidades.

Outros anúncios publicados em jornais brasileiros dos oitocentos associam moda, comércio e literatura naturalista, como o da Chapelaria Inglesa da rua do Ouvidor, veiculado em 6 de dezembro de 1885 na mesma Gazeta de Notícias, que propunha a seus clientes cartolas "das formas Zola e Daudet, [...] muito em moda em Londres e Paris". Os escritores naturalistas, ao que parece, marcaram a moda masculina brasileira de norte a sul do país na década de 1880, pois A Pacotilha do Maranhão de 14 de junho de 1883 já trazia em um grande anúncio de chapéus variados da Fábrica Luso-Brasileira, "O maior sucesso de 1883": "Chapéus de feltro plume à Zola, Flauberte [sic] e Eça de Queirós, com 65 gramas de peso", para "satisfazer a pessoa mais exigente".

Na década seguinte, esses escritores de sucesso atraíam o público leitor de jornais talvez menos por suas obras do que por seu renome e suas figuras públicas. É o que mostram em 5 de dezembro de 1893 e 31 de maio de 1894 os jornais Minas Gerais e A República do Paraná, respectivamente, ao publicarem uma lista de nomes de escritores, dentre os quais Honoré de Balzac, Gustave Flaubert, Émile Zola, Guy de Maupassant, Alphonse Daudet e Edmond de Goncourt, cujos autógrafos eram vendidos a preços compatíveis com aqueles de atores e atrizes franceses célebres, citados na parte inferior do anúncio.

A curiosidade que talvez movesse o leitor de jornal naquele fim de século, ávido por novidades, também conduziria seus olhos para a coluna intitulada "O tempo", na folha carioca O País de 11 de maio de 1895, que veiculava uma singular notícia na qual a literatura serve como trampolim para o interesse pela vida do escritor:

Os amantes de flores que se preparem para obter uma novidade. Trata-se do Jacinto Edmundo de Goncourt. Um floricultor de Harlem querendo ligar o nome daquele festejado literato a uma flor, pediu-lhe autorização escrevendo uma atenciosa carta. Edmundo de Goncourt acedeu aos desejos do delicado floricultor e já deve ter recebido a primeira flor Jacinto Goncourt.

Nota-se também a presença de escritores naturalistas menos conhecidos atualmente dos leitores franceses e brasileiros, 
1 Segundo Antoine Lilti, "A celebridade [...] se autonomiza em relação aos critérios que regem as reputações. Quando um escritor, um ator, um bandido se tornam célebres, a curiosidade que eles suscitam não é mais avaliada pelos critérios próprios de sua atividade de origem. Eles se tornam figuras públicas, que não são mais julgadas em relação a suas competências particulares, mas por sua capacidade em captar e manter esta curiosidade do público" (LILTI, 2014 , p. 14.). Todas as traduções deste artigo são de responsabilidade do autor. como Joris-Karl Huysmans, que aparece na anedota publicada na Gazeta de Notícias de 29 de março de 1912, cinco anos após sua morte, em um texto intitulado "Por que Huysmans odiava a Escola Normal". O jornalista explica que o autor dos romances La Cathédrale e À rebours tece críticas severas à Escola Normal numa obra que apareceria em breve, e que a justificativa era um revide às críticas sofridas por um antigo amigo normalista à época da publicação de seu romance Les Sœurs Vatard.

Esses exemplos da imprensa brasileira foram escolhidos entre outros tantos e revelam que nas décadas de 1880 e 1890, escritores naturalistas franceses como Zola, Maupassant, Alphonse Daudet e os irmãos Jules e Edmond de Goncourt eram bastante conhecidos no Brasil. Sua popularidade se estende até as primeiras décadas do século $\mathrm{XX}$, marcada nos periódicos por notas necrológicas ou de aniversários de morte, por notícias diversas e por alusões às suas obras. As notícias e anúncios apresentados acima provavelmente atraiam a atenção dos leitores. Afinal, numa civilização regida pela imprensa (KALIFA et alii, 2011), de que serviria publicá-las se não houvesse leitores interessados em lê-las? Supomos, assim, que uma flor de nome Goncourt atiçasse a curiosidade da leitora, que os chapéus à moda de Daudet, Zola, Flaubert e Eça de Queirós atraíssem o público masculino, e que os tais "braceletes literários" pudessem se tornar objetos de desejo das donzelas e jovens senhoras amantes da literatura e das artes ou simplesmente das novidades da moda. Também supomos que o leitor e a leitora gostassem de saber o que fazia e pensava Huysmans, um escritor que era lido no Brasil, país católico que, segundo nossas pesquisas, apreciou especialmente sua obra de temática satânica e religiosa. Vemos, assim, que o interesse do leitor brasileiro ultrapassa o gosto pelas obras. Através de seus romances, contos, poesias e de suas participações nos jornais e inserção na vida pública, os escritores se tornavam "celebridades", e seus textos aproximavam-se do mundo das mercadorias, impulsionando o comércio de bens não literários. ${ }^{1}$ A esse respeito, a venda de autógrafos, anunciada nos estados de Minas Gerais e Paraná, colocando em concorrência de preços escritores com atores e atrizes, é bastante emblemática. Os escritores naturalistas, criticados pela elite letrada, mas apreciados pelo público, haviam adquirido capital simbólico 
suficiente nas últimas décadas do século XIX para influir, ainda que involuntariamente, em outras esferas sociais e econômicas, como a moda, determinando gostos e ditando comportamentos. No caso dos escritores naturalistas, esse domínio poderia atingir tanto as classes mais abastadas quanto as de menor poder aquisitivo, mostrando amplo espectro de popularidade desta literatura e indicando mais de um tipo de apropriação do texto naturalista que tanto podia ser lido de modo "sério", em sua vertente cientificista, quanto tomado como literatura popular, por vezes erótica ou pornográfica.

Mostraremos a seguir esses diferentes "naturalismos", ampliando o leque de compreensão da estética para notar como ela circulava de forma variada e complexa no território brasileiro, não se limitando a um único modelo nem se restringindo à predominância de um único autor; num segundo momento, através de dados numéricos, indicaremos a presença e distribuição da literatura naturalista francesa e seus representantes no Brasil entre 1850 e 1914, justificando, assim, a celebridade e a popularidade dos escritores em território nacional, sobretudo nas décadas de 1880 e 1890, dando destaque aos anúncios de livros; finalmente, indicaremos modos de permanência da literatura desses escritores franceses nas primeiras décadas do século $X X$, antes de eles caírem no esquecimento ou se cristalizarem em clichês.

\section{Naturalismos}

A questão que se coloca aqui é o desconhecimento, nos dias de hoje, do alcance que a literatura naturalista francesa obteve em seu primeiro momento de circulação e de sua permanência no campo literário brasileiro. Se escritores como Alphonse Daudet, Jules e Edmond de Goncourt, Joris-Karl Huysmans e Guy de Maupassant não são ignorados pela historiografia literária brasileira do século XX e XXI (mas são raramente mencionados), é certo que o nome de Zola ganhou destaque e centralidade, perpetuando-se como o chefe da "escola naturalista", criador do romance experimental e como "influência" direta sobre os escritores naturalistas brasileiros. No debate da formação da literatura brasileira, o naturalismo científico de Zola é frequentemente reivindicado - e por vezes criticado - por escritores como Aluísio Azevedo, Adolfo Caminha, Júlio Ribei- 
ro, Figueiredo Pimentel, entre outros. Porém, pouco se sabia até o momento da penetração de outros escritores naturalistas franceses no Brasil, das obras que aqui chegavam, circulavam e eram consumidas pelos leitores brasileiros em suas diversas formas: como fragmentos em jornais, citações, menções, livros originais importados, folhetins, traduções.

Centrada no nome de Zola, a crítica brasileira moderna e contemporânea em geral ignora as relações geracionais dos grupos de escritores naturalistas que situam Flaubert e os irmãos Goncourt como os iniciadores da estética e Zola como "aluno" e "êmulo" de Edmond de Goncourt e grande admirador da obra de Flaubert (PAGÈS, 2014, "Maîtres et disciples", p. 61-108). Há também a geração mais jovem, que apoia Zola, Flaubert e os Goncourt em suas lutas no campo literário pela afirmação da estética naturalista, como Guy de Maupassant, Léon Hennique, Henri Céard, Paul Alexis, J.-K. Huysmans (o grupo de Médan), entre outros naturalistas da mesma geração e da geração seguinte (BECKER \& DUFIEF, 2000), sem esquecer Alphonse Daudet, amigo próximo de Zola e dos irmãos Goncourt. Se alguns se aproximam mais do que Zola proporá teoricamente no Roman expérimental, de 1880, todos esses escritores entenderão, como Zola, que o importante é o método de observação e experimentação que fugirá de modelos literários já desgastados, pois cada um praticará o naturalismo de acordo com o seu temperamento (ZOLA, 1881, p. 10). Daí preferirmos falar de naturalismos. No entanto, mesmo quando os escritores se distanciam de Zola e de suas propostas, eles mantêm fidelidade ao método de observação e descrição naturalista, às vezes levado ao paroxismo, próximo do antirromance, como é o caso de J.-K. Huysmans e seus romances da fase religiosa.

A partir da recente possibilidade de exploração de periódicos da Hemeroteca Digital Brasileira (HDB) da Fundação Biblioteca Nacional, é possível visualizar a circulação e recepção desses escritores no Brasil e notar o quanto eles eram, na época de sua primeira circulação e nas décadas imediatamente seguintes, compreendidos em suas particularidades e temperamentos, de maneira bem mais ampla do que hoje, abarcando o naturalismo em seus diferentes subgêneros e modelos (BAGULEY, 2005, "Modes et modèles", p. 69-131). Conseguimos iden- 
2 Não teríamos chegado aos resultados apresentados sem o trabalho criterioso de jovens pesquisadores do curso de Letras da Universidade Federal do Rio de Janeiro na organização e análise do material das fontes primárias - Diego Viana da Costa Pinto (A. Daudet), Eduarda Araújo da Silva Martins (Zola), bolsistas PIBIC-FAPERJ; Michelle Bento Teixeira e Fernanda Felix da Costa (Maupassant), Raisa Cristina Nascimento Santos (teatro naturalista) e Zadig Mariano Figueira Gama (irmãos Goncourt), bolsistas PIBIC CNPq.

3 As datas do recorte temporal inicial obedecem a marcos de publicação inicial de cada autor. A data de encerramento das buscas corresponde à noção de "longo século XIX" de Eric Hobsbawn (ABREU, 2011, p. 115116). Quanto à questão geográfica, para melhor organização dos dados da HDB, classificados por Estados, e conscientes de que esta não era a configuração territorial do Brasil na época estudada, seguimos os contornos das regiões estabelecidos em 1969 pelo IBGE, que não consideram Mato Grosso do Sul, Tocantins, Rondônia, Roraima e Amapá como Estados. tificar pelos Estados brasileiros, ao longo da segunda metade do século XIX e início do século XX, a presença significativa dos naturalismos dos irmãos Goncourt, de Alphonse Daudet, Maupassant e J.-K. Huysmans, com resultados surpreendentes. ${ }^{2}$ Embora Zola seja a referência mais evidente quando se fala do naturalismo francês, ele não constituirá nosso centro de interesse neste artigo, servindo apenas como contraponto numérico e em alguns exemplos, pois visamos principalmente compreender o alcance de outros escritores naturalistas franceses no Brasil.

\section{Por uma cartografia das obras naturalistas francesas no Brasil}

Em pesquisa realizada na HDB até o primeiro semestre de 2015, foram encontradas 210 referências a Joris-Karl Huysmans, 1.121 aos irmãos Goncourt, 1.517 a Guy de Maupassant, 3.267 a Alphonse Daudet e 15.556 referências a Émile Zola, no total de Estados brasileiros, entre 1850 a $1914 .{ }^{3}$ Os dados se referem a anúncios de livros à venda ou disponíveis em bibliotecas e gabinetes de leitura, em francês ou traduzidos, menções, citações, críticas, obras publicadas nos próprios periódicos como folhetim ou em outra modalidade, obituário e notícias diversas.

Desses dados gerais se destaca, deixando de lado o número exponencial de Zola, o número elevado de referências a Alphonse Daudet, escritor atualmente pouco lembrado no Brasil e que teve sua sobrevida na literatura através de quatro obras: as coletâneas de contos Lettres de mon Moulin e Contes du Lundi, seu romance autobiográfico, Le Petit Chose, e o primeiro romance de sua trilogia inspirada em sua terra natal, Tartarin de Tarascon. Essas obras, que passaram a defini-lo, representam, no entanto, apenas uma parcela de sua carreira literária, que é composta em sua maior parte por romances naturalistas, hoje esquecidos. Outro destaque é o número de referências aos irmãos Goncourt por todas as regiões do país. Eles aparecem como as primeiras referências a escritores do grupo, em 1854, marcando a presença precoce de sua produção no Brasil, ou seja, como indicamos anteriormente, respeitando a precedência geracional. 
Dentre os escritores elencados, é Maupassant quem fez mais sucesso nas últimas décadas do século XX com seus contos fantásticos, irônicos e ligeiros, tendo sido absorvido pelo ensino do francês e sua literatura, e mesmo com seus romances, haja vista a recente adaptação para o cinema de Bel Ami, dirigido por Declan Donnellan e Nick Ormerod, em 2012. Tal liderança não se confirma entre os leitores brasileiros do final do século XIX, como comprovam os dados. Ao levarmos em conta as ocorrências das décadas de 1880 e 1890 no Rio de Janeiro e no Brasil como um todo, anos de maior produção desses escritores, será ainda Alphonse Daudet que vencerá com boa distância a disputa com Maupassant, Goncourt e Huysmans, o que nos leva a supor uma preferência do público leitor por este escritor e/ou uma maior aceitação de seu naturalismo "moderado", sem grandes apelos da sensualidade crua, característica em geral mais atribuída a outros autores naturalistas, como o próprio Zola. A presença de Huysmans nesse rol de escritores naturalistas no Brasil é surpreendente, ainda que não muito elevada, pois, com seu estilo cinzelado, não é um autor de apelo popular.

Numa primeira catalogação das ocorrências, identificamos nos Estados brasileiros anúncios de vendas de livros ou livros à disposição em gabinetes de leitura, além daqueles recebidos por redações de jornais, clubes e escolas. Se não podemos afirmar que os livros eram realmente lidos, ao menos chegamos a traçar o mapa da circulação desses volumes disponíveis para a compra ou leitura no Brasil, ao longo da segunda metade do século XIX e início do século XX. Nesse esboço, destacam-se os estados do Maranhão, Pernambuco, Rio de Janeiro e Rio Grande do Sul.

A maior parte das ocorrências a Daudet corresponde aos estados do Maranhão e Rio de Janeiro. Entretanto, 115 referências no Maranhão dizem respeito a anúncios de uma mesma livraria, repetidos em dois periódicos diferentes ao longo de dois anos, nos quais só se encontram 3 obras de Daudet, enquanto no Rio de Janeiro há uma maior variedade de obras e livrarias. O Rio Grande do Sul mostrou-se numericamente expressivo, com 78 ocorrências de diversas livrarias, mostrando uma variedade maior de obras do que a do Maranhão. A partir dos anúncios, depreende-se a lista de livros disponíveis para o público leitor brasileiro entre 1860 e 1914, com destaque para 
a década de 1880. Ela perfaz quase toda a carreira do escritor, desde sua primeira publicação em 1858 até três anos antes de sua morte, com La Petite Paroisse. Destacamos alguns títulos que aparecem em português (em tradução): A Firma Social Fromont e Risler; O Nababo; Contos; Mulheres de artistas; Aventuras Prodigiosas de Tartarin de Tarascon; O Imortal; A Capelinha; Os Reis no Exílio; A Primeira Casaca; O Cerco de Paris; A Evangelista; Teatro, sem contar aqueles que são nomes próprios como Sapho e Numa Roumestan. Dos livros à disposição do leitor brasileiro pouco tempo após sua publicação na França temos Sapho (1884) e L'Immortel (1888), presentes no mesmo ano no Brasil e Le Nabab (1884), Port-Tarascon (1890) e La Petite Paroisse (1895) no ano seguinte.

A primeira ocorrência encontrada entre todos os autores se deu em 27 de novembro de 1854 no Diário do Rio de Janeiro, no anúncio da Livraria de B. L. Garnier dos "Livros ultimamente chegados", que oferece o opúsculo La Lorette de Jules e Edmond de Goncourt, editado por Dentu no verão de 1853, reunindo uma série de textos curtos do gênero "fisiologia", em sua origem intitulados "Lèpres modernes" - prenúncio de personagens femininas naturalistas que virão - cuja tiragem de 6.000 exemplares se esgotou em apenas oito dias, na França. Dentre os 101 anúncios de venda de livros dos Goncourt no Maranhão, 32 estão no Diário do Maranhão e 69 estão na Pacotilha. Os do Diário do Maranhão vão do dia 28 de abril de 1896 até 16 de junho de 1898. Na Pacotilha, de 21 de janeiro de 1896 até 25 de junho de 1897. Como para Daudet, através da comparação entre Rio de Janeiro e Maranhão, pode-se inferir que o resultado quantitativo não aponta para a circulação de títulos variados de romances. Os jornais maranhenses revelam a circulação de apenas um romance dos Goncourt, Soror Philomena, em português; já os jornais do Rio de Janeiro mostram uma maior variedade de títulos, disponíveis em um intervalo de tempo mais longo, desde de 1854 até 1898.

Na região sul do país os anúncios de venda de livros se dão somente no Rio Grande do Sul. Ojornal A Federação publica o anúncio das "ultimas obras literárias francesas" à venda na Livraria Americana de Carlos Pinto \& C. Sucessores, de 28 de maio a 28 de junho de 1887. Nesses 30 dias, ele foi repetido 15 vezes, comunicando a venda de Les Frères Zemganno e Renée Mauperin, além de diversas obras de Daudet, Zola, Maupassant 
e Turgueniev. O periódico volta a anunciar obras dos irmãos Goncourt nos dias 16 e 17 de outubro de 1911, trazendo uma lista bem extensa de obras, disponíveis na Livraria Universal de Carlos Echenique, como La Faustin, Charles Demailly, Madame Gervaisai e o Journal. O total de anúncios no país também aponta, como no caso de Daudet, para a circulação de um número expressivo de obras dos irmãos Goncourt, lista bastante variada e completa, mostrando a penetração, do norte ao sul do país, desses autores partidários da écriture artiste e da narrativa segmentada - fatura bem distinta daquela de Zola. Dos títulos encontrados, apenas Soror Philomena parece ter sido traduzido, encontrando-se à venda nos Estados do Rio de Janeiro, São Paulo, no Rio Grande do Sul, Pernambuco e Maranhão, em coleções econômicas. La fille Élisa estava disponível no Brasil apenas alguns meses após sua publicação na França, mostrando mais uma vez que havia aqui público interessado em ler e livreiros interessados em vender, o que fazia com que os livros atravessassem rapidamente o Atlântico.

Para Maupassant, das 1.517 referências, 165 são anúncios nos quais se encontra uma boa parte de seus principais títulos, como Contes et nouvelles, Fort comme la mort, Pierre et Jean, Le Père Milon e contos diversos. A hipótese de um Maupassant desconhecido antes do sucesso de "Boule de suif", em 1880, é confirmada pelos dados, pois nenhuma referência foi encontrada nos periódicos brasileiros antes dessa data. Diferentemente de Daudet, revelado sobretudo como um escritor de romances naturalistas, Maupassant era lido entre 1880 e 1914 principalmente por seus contos, dos quais 71 foram traduzidos e publicados em periódicos, meio mais usual de divulgação do gênero. Em alguns casos, o tempo da publicação francesa e a sua tradução brasileira foi bem curto: "O Garrafão" "'Le Petit Fût" - 8 meses), "O Horla" ("Le Horla" - 25 dias), "A baronesa" ("La Baronne" - menos de 3 meses), e o romance Pierre et Jean, lançado na França no verão de 1887 e publicado em português no Brasil seis meses depois.

O caso de Huysmans dentro do grupo naturalista é peculiar. Através dos anúncios de livros e de notas de acervos de bibliotecas privadas temos a indicação de como os romances de Huysmans foram recebidos e circularam no Brasil. Embora tenhamos encontrado anúncios de suas obras naturalistas stricto sensu - Les sœurs Vatard, En rade, A vau-l'eau, À rebours 
- o leitor brasileiro se interessará, sobretudo, por aquelas produzidas durante e após sua "conversão" ao catolicismo, como comprova a presença de Là-bas, romance sobre o satanismo e a missa negra, e de En route, romance sobre a conversão, muito comentado nas críticas dos jornais brasileiros, no anúncio da Livraria Católica de J. A. Savin, vendido como "Novidades" por 4000 réis, no Rio de Janeiro, que a folha católica $O$ Apóstolo veicula de 1 de abril a 3 de junho de 1896. La Cathédrale também pôde ser lido por brasileiros. Huysmans aparecerá traduzido no anúncio de "Livros Religiosos - últimas publicações católicas recebidas pela Livraria Econômica", de Recife, com Santa Lydwina por 3500 réis e $A$ caminho (confissões) por 4000 réis, publicado em A Província de maio a julho de 1903. O mesmo jornal lançará em maio de 1904 um anúncio da mesma livraria oferecendo a tradução do romance La Cathédrale, "o poema em prosa da simbólica, o maior monumento da literatura cristã dos últimos tempos". Em 1906, há no Rio de Janeiro uma tradução de En rade intitulada $O$ Castelo de Lourps. Vemos, assim, uma recepção peculiar desse escritor naturalista entre leitores brasileiros, sobretudo no início do século XX. Les foules de Lourdes, seu último romance, de 1906, estava à disposição dos leitores do Rio Grande do Sul no mesmo ano.

Destacamos também a presença desses escritores naturalistas - excetuando Huysmans - no seio de uma coleção de romances que foi anunciada por várias livrarias de norte a sul do país, como por exemplo a A. P. Ramos de Almeida \& Sucessores, do Maranhão, e a Livraria Americana de Carlos Pinto \& C. Sucessores (Porto Alegre-Pelotas-Rio Grande), do Rio Grande do Sul, que a disponibilizavam para seus clientes. Trata-se da Coleção Econômica da Laemmert \& C. Editores (Rio de Janeiro-São Paulo-Pernambuco), criada com sucesso em julho de 1895 e que chega ao seu $28^{\circ}$ volume em julho de 1898, todos traduzidos. Lançando um ou dois romances por

4 No mesmo anúncio do Diário do Maranhão de 28 de abril de 1896, a Livraria Popular Luiz Magalhães \& C. vendia os livros da Coleção Econômica por 1000 réis, enquanto o Livro de uma sogra, de Aluísio Azevedo, custava 4000 réis e os Contos da Carochinha, de Figueiredo Pimentel, 3000 réis. mês, esta coleção popular, cujos volumes eram vendidos a 1000 réis, ${ }^{4}$ tem como $1^{\circ}$ número As aventuras de Tartarin de Tarascon, seguidas de Tartarin nos Alpes, de Daudet que, segundo nota de A Notícia de 1-2 de agosto de 1895, "foi esgotado em dois dias". $\mathrm{O} 2^{\circ}$ número também coube a um escritor naturalista, Guy de Maupassant, com seu Pedro e João; o $4^{\circ}$ foi O Sonho, de Zola, seguido de Soror Philomena, dos Goncourt. O $9^{\circ}$ romance da coleção foi Vogando e o $21^{\circ}$ Forte como a Morte, ambos de Mau- 
passant. Zola ocupou também o $26^{\circ}$ lugar com Magdalena Férat. Daudet terá ainda os $12^{\circ}$ e $27^{\circ}$ volumes, com O Nababo e Os Reis no exílio; sem contar Um Búlgaro, do escritor naturalista russo Ivan Turgueniev, com o $19^{\circ}$ lugar da coleção. Esses romances naturalistas convivem na Coleção Econômica da Laermmert com obras de escritores contemporâneos, alguns deles podendo ser considerados contrários ao naturalismo, como o popular Georges Ohnet e Paul Bourget, indicando uma convivência de estéticas e o gosto variado dos leitores que se aproxima do que vimos com o "bracelete literário".

A importante presença da literatura naturalista nessa coleção popular vai ao encontro dos números obtidos em nossa pesquisa, ratificando a década de 1890 como aquela de maior popularidade desses escritores no Brasil. A permanência da literatura naturalista também será assegurada por outras vias, como veremos a seguir, confirmando que, no século $X X$, a literatura naturalista francesa permanecia na vida cultural brasileira.

\section{A literatura naturalista em outras artes}

Os dados da pesquisa em periódicos brasileiros de 1850 a 1914 revelam que, ao contrário do que costumam afirmar críticos e compêndios de História Literária, e apesar de se notar uma queda das referências aos escritores naturalistas franceses após a década 1890, há uma permanência de seus nomes e referências às suas obras, talvez reduzida após 1914 devido aos problemas de comunicação e circulação de mercadorias ocorridos por conta da Primeira Guerra Mundial. Um dos aspectos mais interessantes dessa permanência tem sido notado nas duas primeiras décadas do século XX: a popularidade de alguns desses escritores e suas obras se espraia para outras formas de produção artística, como atestam anúncios e notícias publicados à época nos jornais.

Antes, já havíamos notado o interesse pela cena artística europeia em inúmeras notas sobre espetáculos que eram levados na Europa. Assim, na edição de 18 de outubro de 1895, o Jornal do Recife traz a programação dos teatros Gymnase e Vaudeville em Paris para os anos de 1895-1896. Dentre as peças enumeradas estão as novas "Manette Salomon, peça em 10 
quadros de Edmond de Goncourt; [...] La Petite Paroisse, peça em 4 atos de Daudet"; e entre as reprises encontramos "Sapho, peça em 5 atos de Daudet e Belot". Em 1896, na edição de 3 de outubro, o mesmo jornal anuncia na coluna "Teatros e Salões" a montagem da ópera Sapho, prevista para a Exposição Universal de Paris de 1900, "cujo libreto foi extraído do célebre romance de A. Daudet", com música do "infatigável Massenet". O jornal publicará na mesma coluna de 13 de janeiro de 1898 que "o libretista italiano Leopold Marenco extraiu da 'Arlésienne' de Daudet o libreto de uma ópera em quatro atos, sendo a música de Francesco Cilea". A ópera Sapho em 5 atos com música de Jules Massenent e libreto de Henri Cain e Arthur Bernède foi composta em 1896 e apresentada pela primeira vez em 27 de novembro de 1897, no Opéra-Comique de Paris. A Arlésienne, ópera em 3 atos com música de Francesco Cilea e Libreto de Leopoldo Marenco foi representada pela primeira vez, no mesmo dia, no Teatro Lírico de Milão, o que atesta a atualidade das notícias do jornal de Recife. Originalmente em quatro atos, como anuncia o periódico, haverá uma segunda versão em 3 atos feita no ano seguinte. Mais uma vez, é notório o interesse do público brasileiro em relação à obra de Daudet, como vimos acima e veremos a seguir, pois ela estará muito presente também em outras formas de adaptação.

No teatro, podemos igualmente afirmar que há uma relativa continuidade no que diz respeito ao repertório naturalista, através de montagens de companhias estrangeiras, mas também nacionais. A título de exemplo, os leitores do Jornal do Brasil de 9 de julho de 1903 podiam querer assistir, após lerem o anúncio, à peça Musotte de Guy de Maupassant e Jacques Normand - adaptação teatral da novela L'enfant, de 1882, que foi encenada pela primeira vez em Paris no Théâtre du Gymnase em 4 de março de 1891 -, apresentada pela companhia portuguesa Souza Bastos no teatro Apolo do Rio de Janeiro; e, se fossem muito afeiçoados ao escritor naturalista, iriam ver no dia seguinte a única representação de Boule de Suif - peça adaptada por Oscar Méténier a partir do conto homônimo de grande sucesso de 1880 -, apresentada pela companhia do ator e

5 Os dois anúncios se encontram lado a lado no canto direito da página 6 do jornal. diretor francês André Antoine em sua turnê no Rio de Janeiro. ${ }^{5}$

André Antoine criou o Théâtre Libre - mais tarde renomeado Théâtre Antoine - em 1887, palco principal para a 
6 A série de 14 publicações da coluna foi descoberta no âmbito de nossa pesquisa e constitui, até nova informação, fonte primária inédita em pesquisas acadêmicas.

7 Zola adapta oromance homônimo de 1867 para o teatro e a peça estreia em Paris, no Théâtre de la Renaissance, em 11 de julho de 1873.

$8 \mathrm{O} \quad \mathrm{r}$ o m a n c e L'Assommoir foi adaptado para o teatro em 1879 por William Busnach e Gustave Gastineau com a colaboração de Zola. O Mesmo Busnach adaptará o romance Nana para a cena em 1881. encenação de peças naturalistas na França, algumas escritas exclusivamente para a encenação do grupo, outras adaptadas de romances conhecidos. Além do repertório, o naturalismo de Antoine se dá sobretudo na representação, com destaque para os figurinos, os cenários e principalmente o modo realista de atuar. Trata-se, em sua origem, de um teatro experimental que trouxe grande inovação para o panorama teatral francês. Em julho de 1903, a trupe de Antoine encenou 26 peças no Teatro Lírico do Rio de Janeiro, lugar suntuoso e de prestígio à época, dentre as quais La Fille Élisa de Edmond de Goncourt, Jacques Damour de Zola, e Boule de Suif de Maupassant. Suas apresentações foram vistas por um público variado, mas em geral abastado, composto por intelectuais e políticos - o presidente da república e sua família compareceram a mais de uma récita -, como indica a coluna "Antoine - Na sala e nos bastidores" publicada na Gazeta de Notícias durante mês de julho. ${ }^{6}$

A recepção das peças naturalistas no início do século XX, num espaço de prestígio como o Teatro Lírico, contrasta aparentemente com aquela das peças de Zola apresentadas no Rio de Janeiro na década de 1880, que parece ter tido um alcance mais popular. Atento ao sucesso da obra romanesca de Zola, em junho de 1880, o ator e empresário Furtado Coelho monta, no Teatro Lucinda do Rio de Janeiro, Thérèse Raquin, ${ }^{7}$ com tradução do poeta Carlos Ferreira, obtendo relativo sucesso de público e elogios à montagem e à atuação da atriz Lucinda Simões. Em 1881, será a vez da atriz e empresária Ismênia dos Santos, igualmente atenta às novidades do teatro moderno, de montar L'Assommoir e Nana, nos teatros São Luís e Recreio Dramático do Rio de Janeiro (FARIA, 2001, p. 245-261; FARIA, 2012, p. 296-305). ${ }^{8}$ Lucinda Simões e Furtado Coelho, coerentes com a linha do teatro realista e naturalista que adotavam, montaram ainda, em 1881, O Irmão mais velho de Alphonse Daudet, segundo indica A Revista Ilustrada do Rio de Janeiro de 5 de novembro. Em 7 de outubro de 1891, o Teatro Lucinda estreia, de acordo com os anúncios do jornal $O$ Tempo de 9 de setembro, $1^{\circ}, 6$ e 7 de outubro a peça $O$ obstáculo, do mesmo autor, traduzida pelo Dr. Macedo de Aguiar.

Ao contrário do que poderíamos deduzir pelas informações veiculadas pelos compêndios de História Literária e livros didáticos, Alphonse Daudet se afirmará como um autor 
9 Adolphe Belot (18291890), hoje pouco lembrado, foi autor de literatura popular erótica e maliciosa de imenso sucesso editorial.

10 Trata-se da adaptação de L'Assommoir, mencionada anteriormente, já montada em 1881 pela atriz baiana Ismênia dos Santos, no Teatro São Luís. de prestígio e grande interesse no Brasil por sua produção naturalista. Sapho, romance de 1884, publicado por Georges Charpentier, editor dos naturalistas, será adaptado para o teatro por Daudet e Adolphe Belot. ${ }^{9}$ Segundo os dados encontrados, essa peça obteve uma longa carreira no Brasil. A Revista da Semana do Rio de Janeiro anunciava em 22 de junho de 1902 a peça Sapho, "obra-prima de Daudet, teatrata por Belot, no Teatro Apolo", com a célebre atriz francesa Réjane no papel principal - informação corroborada pelo Jornal do Recife de 14 de outubro, ao reportar notícia do Correio da Manhã, do Rio de Janeiro: "A gloriosa atriz deu na América do Sul, em 3 meses, de 1 de junho a 30 de setembro, 65 récitas, das quais: 24 no Rio de Janeiro, 6 em S. Paulo, 1 em Santos, 8 em Montevidéu, 25 em Buenos Aires e 1 em La Plata." Em 3 de junho de 1906 será ainda Sapho, de Daudet e Belot, que a Revista da Semana anunciará, desta vez na interpretação da atriz italiana Tina di Lorenzo, em sua primeira turnê pelo Brasil. Do repertório da atriz ainda consta Musotte, de Maupassant, também apresentada em 1903, como visto anteriormente.

Sapho ainda será representada em 1909 e 1910, segundo fontes encontradas. O hebdomadário Rua do Ouvidor, publicado aos sábados, anuncia no volume de 13 de maio de 1909, dedicado às comemorações da Abolição da Escravatura, que o Teatro Carlos Gomes apresentou, pela Companhia de Teatro Príncipe Real, de Lisboa, Sapho de Daudet e que ainda levará A Taverna. A Revista da Semana de 16 de maio trará mais informações sobre as apresentações das peças naturalistas, lembrando que $A$ Taverna era "extraída do célebre romance de Zola", ${ }^{10}$ destacando "as aptidões cênicas do ator Álvaro" e o talento da "menina Risoleta Carvalho, pela inteligência e desembaraço revelados no desempenho da pequena Nana". Elogia a interpretação de Maria Falcão, "que tem progredido muito, e da Sra. Isaura Ferreira que deu boa conta da Divonne", na peça Sapho.

O privilégio de assistir ao repertório teatral naturalista não era exclusivo da capital do país, pois em 13 de junho de 1909 A Província, folha de Pernambuco, anunciava a visita da companhia da atriz Angela Pinto para dez récitas de um "moderno repertório" que incluía Sapho. Em 1910, o Jornal do Recife de 8 de outubro confirmava que a mesma intérprete de Sapho no Teatro Carlos Gomes do Rio de Janeiro, como visto acima, a 
atriz portuguesa radicada no Brasil Maria Falcão, integrante da Companhia Dramática do também português Eduardo Victorino, encenador dos mais atuantes na cena brasileira, promete estar no Recife até o fim de 1910, para apresentar, dentro de um vasto repertório, Sapho de Daudet e A Taverna de Zola. Em 1911, como anuncia a seus assinantes A Pacotilha do Maranhão de 3 de janeiro, vemos que a companhia de Maria Falcão ainda mantém em seu repertório Sapho e A Taberna.

Como se pode notar, o repertório naturalista francês no teatro, certamente sustentado pelo sucesso de vendagem dos romances a partir dos quais as peças foram adaptadas e pelo renome ou celebridade de seus autores, mantém-se na pauta teatral de companhias nacionais e estrangeiras visitando o país, mesmo após o momento mais forte de produção dessa estética, pois além da morte dos principais expoentes do primeiro naturalismo, as novas gerações procuravam novas vias para o gênero romance. Contrariando as Histórias Literárias que o veem como expirante na última década do século XIX e definitivamente morto no século $\mathrm{XX}$, o naturalismo ganhará novo fôlego, pelo que os periódicos nos têm revelado, em um ramo da atividade cultural e de entretenimento novo e em ascensão à época: o cinema.

Em 20 de janeiro de 1909, o jornal carioca O Século, de propriedade de Brício Filho, anunciava à página 3 , na coluna "Theatros", que "haver[ia] [...] mais um espetáculo no Teatro Lírico, onde os 'films de arte' vão sendo muito apreciados e aplaudidos" Na terceira parte do programa "será [ainda] exibido o novo 'film' 'A Arlesiana', extraído de um romance de Daudet e musicado por Bizet". Trata-se, provavelmente, do filme L'Arlésienne, baseado na novela homônima de Daudet, publicada em 1869 na coletânea Lettres de mon moulin, e dirigido em 1908 por Albert Capellani, pioneiro do cinema mundial e das adaptações cinematográficas de textos literários. Também no Rio de Janeiro, em 24 de março de 1909, a Gazeta de Notícias anunciava uma obra de Guy de Maupassant no Cinema-Pathé. Tratava-se da "primeira representação do Film d'Art - O velho Milon, - Extraído do célebre romance de Mr. Guy de Maupassant. Empolgante trecho da guerra franco-prussiana de 1870". Um aviso esclarecia que "Film d'Art não é nome genérico para qualquer composição, como tem sido falsamente aplicado à baixa produção, porém uma nova classe de fitas cinemato- 
gráficas executada sob os auspícios de tudo quanto o teatro francês possui de ilustre".

A literatura parece, assim, ter criado um nicho no que será chamado mais tarde de "sétima arte" pois, como podemos notar no anúncio do Século e no aviso explicativo do Cinema-Pathé, fará parte dos chamados "filmes de arte", distinguindo-se das cenas de ação e cômicas, documentários e curtos dramas habitualmente apresentados. $O$ velho Milon é muito provavelmente a versão muda realizada por Henry Houry e Firmin Gémier em 1908 para a novela Le Père Milon, que Maupassant havia publicado em 22 de maio 1883 no Gaulois e que foi lançada postumamente em 1899. Le Père Milon será o primeiro de uma série de filmes dirigidos por Henry Houry. Como ator, ele trabalhou em peças no Théâtre Antoine, como em La Clairière do escritor naturalista Lucien Descaves. Firmin Gémier iniciou sua carreira no Théâtre Antoine, onde trabalhou de 1906 a 1919, participando de várias peças do repertório naturalista do diretor, antes de criar o Théâtre national populaire, em 1920. Desse modo, a ponte entre o teatro naturalista e o cinema se torna mais evidente, a partir das relações tecidas no Théâtre Antoine.

Mas o privilégio dos "filmes de arte" não se restringirá ao Rio de Janeiro, pois o Jornal do Ceará de 18 de fevereiro de 1910 anuncia na seção "Cinemas" a chegada em breve das "esplêndidas [sic] films 'O mártir da questão Dreyfus', de grande sucesso; 'Assommoir' de Zola, film d'art com 1500 metros, dividida [sic] em duas partes, da casa Pathé Frères", fitas baseadas na obra de Zola e no palpitante e polêmico Affaire Dreyfus que trouxe grande popularidade a Zola - projeções que a edição de 23 de fevereiro do jornal confirmará. Pelas datas, procedência e extensão da película, cremos que o filme em questão é o francês L'Assommoir (40 minutos), realizado em 1909 por Albert Capellani (diretor que filmara L'Arlésienne de Daudet, de 1908). Quanto a "O mártir da questão Dreyfus", trata-se muito provavelmente de um filme de 1908, produzido pela firma Pathé (como afirma o Jornal do Ceará), realizado pelo mesmo Capellani e por Ferdinand Zecca, que havia rodado a versão de L'Assommoir de 1902 (BECKER et alii, 1993, p. 78-79).

Como para o teatro, as fontes também indicam a forte e inesperada presença de Alphonse Daudet nas adaptações dos romances para o cinema. Em 1910, o Cinema-Pathé do Recife 
11 Osite do IMDb (www. imdb.com) indica os atores Cécile Guyon e Charles Krauss como os protagonistas desta versão, o que está em acordo com as informações do anúncio. anuncia no jornal A Provincia de 31 de agosto o filme A Arlesiana. Provavelmente, trata-se do filme de 1908, também do diretor Albert Capellani. No mesmo ano, o filme é reapresentado no Cinema-Pathé, como anuncia o Jornal do Recife de $1^{\circ}$ de setembro. Em anúncio do Theatro Cinema Palace, A Pacotilha do Maranhão de 21 de junho de 1913 traz em letras garrafais e com grande destaque na página o filme Sapho, "verdadeiro e único sucesso", "verdadeiro sucesso cinematográfico", "adaptação cinematográfica do célebre romance de Alphonse Daudet. Editado pela laureada fábrica Eclair-Paris - Por autorização especial - 4 atos, 1800 metros, 325 quadros". Tudo leva a crer que seja o filme de 1912, realizado por Emile Pierre Chautard (1864-1934), ator e diretor americano de origem francesa, tendo trabalhado no Teatro do Odéon no final do século XIX, onde certamente encontrou Antoine. Principal diretor artístico da Association des Comédiens et Auteurs Dramatiques, dedicou-se aos "filmes de arte", pela Société Eclair (terceira produtora de filmes franceses, depois da Gaumont et Pathé, até 1918). ${ }^{11}$ Esse grande anúncio ainda traz a dedicatória original do romance de Daudet - "Aos meus filhos quando tiverem 20 anos" -, estabelecendo um vínculo direto entre o cinema e a literatura e mostrando que se trata de um filme para adultos. $\mathrm{O}$ anúncio será reformulado nos dias 23 e 25, quando outras películas ganharão destaque. O filme também havia passado anteriormente no Recife, segundo A Província de 26 de fevereiro. A Pacotilha do Maranhão ainda anuncia na edição de segunda-feira, 15 de setembro de 1913, o filme a ser apresentado no domingo: "Apresentação do grandioso drama da vida real, extraído da imortal obra de Afonso Daudet" - O NABABO - "Sucesso indescritível! Êxito Colossal!", em que destaca o caráter naturalista na abordagem do que Zola chamaria de tranche de vie.

Para não sermos exaustivos, diremos que, segundo anúncios e notas encontrados em periódicos brasileiros, outras adaptações fílmicas da obra de Daudet passarão no Maranhão, em Pernambuco, no Paraná e no Rio de Janeiro entre 1913 e 1914, notadamente O Nababo, Jack e Sapho, mostrando mais uma vez a circulação, a permanência e a popularidade em nosso país da obra naturalista desse escritor e a sincronia entre Europa e Brasil no que concerne à produção cultural. 


\section{Estética naturalista e cultura globalizada}

Distante da ideia de atraso cultural propagada pela crítica hegemônica ao longo do século XX, os dados apresentados sumariamente neste artigo provam efetivamente a presença e circulação da literatura naturalista francesa no campo literário brasileiro, cobrindo o território nacional por um longo período. Não discorremos aqui sobre a circulação de folhetins, traduzidos e publicados em periódicos dos diversos Estados do país, o que certamente aumentaria o número de textos literários à disposição do público leitor brasileiro durante várias décadas, marcando sua formação literária e cultural. Os anúncios de livros à venda ou doados a instituições são apenas uma pequena amostra do que realmente circulou da literatura naturalista francesa no Brasil. Não nos ativemos tampouco à repercussão da morte desses escritores em obituários que, segundo Lilti, "entre as notícias que os jornais dão das pessoas célebres [...] é, evidentemente, umas das mais notáveis" (LILTI, 2014, p. 104). Daudet, Goncourt, Maupassant e inclusive Huysmans (sem falar de Zola) mereceram longos artigos necrológicos e notas em diversos jornais pelas regiões do país, mostrando que, no Brasil, o naturalismo francês foi acolhido em sua diversidade e não se reduziu àquele praticado por Zola. Nesse sentido, há de se notar reportagens e notas que, posteriores à data de seus óbitos, rememoram seus aniversários de morte, comentam suas obras e mesmo seus projetos literários, como é o caso da criação e funcionamento da Academia Goncourt. Os dados que apresentamos trazem a novidade da forte presença da obra de Alphonse Daudet que antes não conhecíamos, uma recepção dos Goncourt e de Huysmans que também não era suspeitada. Além disso, muitas notas e artigos críticos sobre as obras e a vida literária dos escritores apontam para um conhecimento real do que eles produziam e do que propunham para a estética naturalista, guardadas as peculiaridades de cada um.

Retornando ao início do texto, mais precisamente ao "Bracelete Literário", podemos perceber, nesse anúncio de 1884, uma hierarquia de estéticas. Em primeiro lugar, no gosto das senhoras estão os escritores naturalistas, em seguida os românticos, depois os clássicos e, enfim, autores diversos, onde encontramos Daudet. Vale notar que, longe de se excluírem 
umas às outras num processo de sucessão caro ao didatismo das Histórias Literárias, as estéticas convivem harmoniosamente nos gostos das senhoras, inclusive podendo compor o mesmo bracelete das "ecléticas". A hierarquia parece sobretudo indicar o que estava no auge da moda na década de 1880 - a literatura naturalista -, o que ajuda a entender o uso nomes de escritores associados em anúncios a objetos à venda, como no caso dos chapéus, aproximando a literatura do marketing e do mundo das mercadorias. Na década seguinte, a celebridade dos escritores naturalistas atingirá seu apogeu, o que nos mostra a venda de autógrafos equiparando escritores e atores. Não queremos afirmar ingenuamente com isso que outros escritores e outras estéticas não fizessem sucesso na mesma época; o próprio bracelete e a lista de livros da Coleção Econômica da Livraria Laemmert sugerem justamente o contrário. Porém, os dados de nossa pesquisa parecem comprovar o grande sucesso da literatura naturalista francesa no Brasil na década de 1880, aumentando na seguinte e começando a declinar a partir do século $X X$, ao mesmo tempo que ganha terreno migrando para outras linguagens. As adaptações teatrais de trupes estrangeiras e nacionais e os filmes que cruzaram o Atlântico em tão pouco tempo parecem assegurar, no final do século XIX e início do século $X X$, a permanência das obras naturalistas, mostrando que elas perduraram no gosto das pessoas. Além disso, peças e filmes oferecem a oportunidade de uma sobrevida das obras mesmo entre os iletrados, alargando ainda mais o público conhecedor dessa estética.

A literatura naturalista, em geral rejeitada pela crítica brasileira dominante, mas que paradoxalmente se canonizou, possuiu assim o seu lugar na cultura brasileira, transitando por longo período entre a elite letrada ou leitores interessados no caráter científico e social da estética e uma camada mais ampla e menos especializada de leitores, atraída pelos sucessos de escândalo em cenas mais realistas e por vezes picantes ou sórdidas - o que certos livreiros e editores brasileiros à época entenderam muito bem ao explorar o viés erótico e até mesmo pornográfico do naturalismo. 


\title{
REFERÊNCIAS
}

ABREU, Márcia. A circulação transatlântica dos impressos: a globalização da cultura no século XIX. Livro. Revista do NELE, São Paulo, no 1, p. 115-116, maio de 2011.

BAGULEY, David. Le naturalisme et ses genres. Paris : Nathan, 2005. BECKER, Colette et alii. Dictionnaire d'Émile Zola; sa vie, son œuvre, son époque suivi du Dictionnaire des RougonMacquart. Paris: Robert Laffont, 1993.

BECKER, Colette \& DUFIEF, Anne Simone (dir.). Relecture des "petits" naturalistes. Paris: Université Paris X, 2000.

FARIA, João Roberto. Ideias Teatrais: O século XIX no Brasil. São Paulo: Perspectiva- FAPESP, 2001.

(dir.). História do Teatro Brasileiro, v. 1. São Paulo: Perspectiva, 2012.

KALIFA, Dominique et alii (dir.). La civilisation du journal; histoire culturelle de la presse française au XIX ${ }^{\mathrm{e}}$ siècle. Paris: Nouveau monde, 2011.

LILTI, A. Figures publiques; l'invention de la célébrité 1750-1850. Paris: Fayard, 2014.

PAGÈS, Alain. Zola et le groupe de Médan; histoire d'un cercle littéraire. Paris: Perrin, 2014.

ZOLA, Émile. Le roman expérimental. $5^{5}$ éd. Paris: Charpentier, 1881.

\begin{abstract}
From literature to cinema: French naturalism in nineteenth-century Brazilian culture

This paper focuses on the presence of French naturalist literature from the second half of the nineteenth century to 1914, highlighting its importance and diversity in the Brazilian literary field and its survival by means of association with other forms of art, such as theatre and cinema. In order to prove this point, data are presented which confirm the circulation of the works of French naturalist writers throughout the period, reaching a varied public, and show their strength outside the literary sphere per se, causing an impact on fashion and customs.
\end{abstract}

Keywords: naturalist aesthetic; Brazilian culture; Brazilian press; naturalist theatre; cinema. 